\title{
A CASE OF BILATERAL SPHENOIDAL EMPYEMA WITH MAINLY OCULAR MANIFESTATIONS
}

BY

D. Stenhouse Stewart

HULL

E. B., a confectioner, aged 42 , was seen by $\mathrm{Mr}$. Cridland at Stafford on January 19, 1928, and was admitted under his care to the Wolverhampton and Midland Counties Fye Infirmary for complete investigation of possible causes of the serious reduction of visual acuity and defective colour vision which had gradually developed during the previous twelve months.

The patient had experienced severe frontal headaches since midsummer, 1927, and from September colours seemed darker and were misinterpreted, with resulting dificulty in performing his work which consisted mainly of applying coloured piping to iced cakes. He noticed particularly a blue veil over white and other light objects, and was thus unable to gauge the amount of blue to add to inferior icing sugar.

In December, 1926, he was dazed for some hours following unconsciousness from an accident, when an electric shock caused him to fall and strike his left temple and the back of his head.

The first pair of fields, for a $0.50 \mathrm{~cm}$. white object was taken on January 21, 1928, when his central visual acuity was :-
$0 . \mathrm{D} .=6 / 18$ partly; $\overline{\mathrm{c}} .+0.25$
D. sph. $\simeq+0.75$ D. cyl.

$$
\text { ax } 50^{\circ}=6 / 18
$$
0.S. $=6 / 18 ; \bar{c} .+0.75$ D. cyl. ax. vert. $=6 / 12$
Under cycloplegia :-

$$
\begin{aligned}
& \text { O.D. }=\overline{\mathrm{c}} .+0.75 \text { D. sph. } こ+1.00 \text { D. cyl. ax. } 30^{\circ}=6 / 24 \\
& 0 . \mathrm{S} .=\overline{\mathrm{c}} .+1.25 \text { D. sph. } こ+0.25 \text { D. cyl. ax. vert. }=6 / 18
\end{aligned}
$$

Macular perception of coloured objects up to $1^{\circ}$ visual angle in size was uncertain with the left eye, and definitely poor with the right. Red was described as dark chocolate, white as bluish white, blue as dark bluish, green as very dark blue, and yellow as dark salmon. It was evident that he mistrusted himself from past experience.

Beyond this, and his statement that, when he was reading, the word he was looking at sometimes, seemed to fade out, no scotoma could ever be demarcated in this case, throughout which there were no ophthalmoscopic signs whatever; his blood Wassermann was negative, his urine was normal, and no other abnormality was detected in his central nervous system.

As he had a nasal discharge he was examined by Mr. A. Lowndes Yates, honorary rhínologist to the institution on January $\mathfrak{q 6}$, and given treatment, 

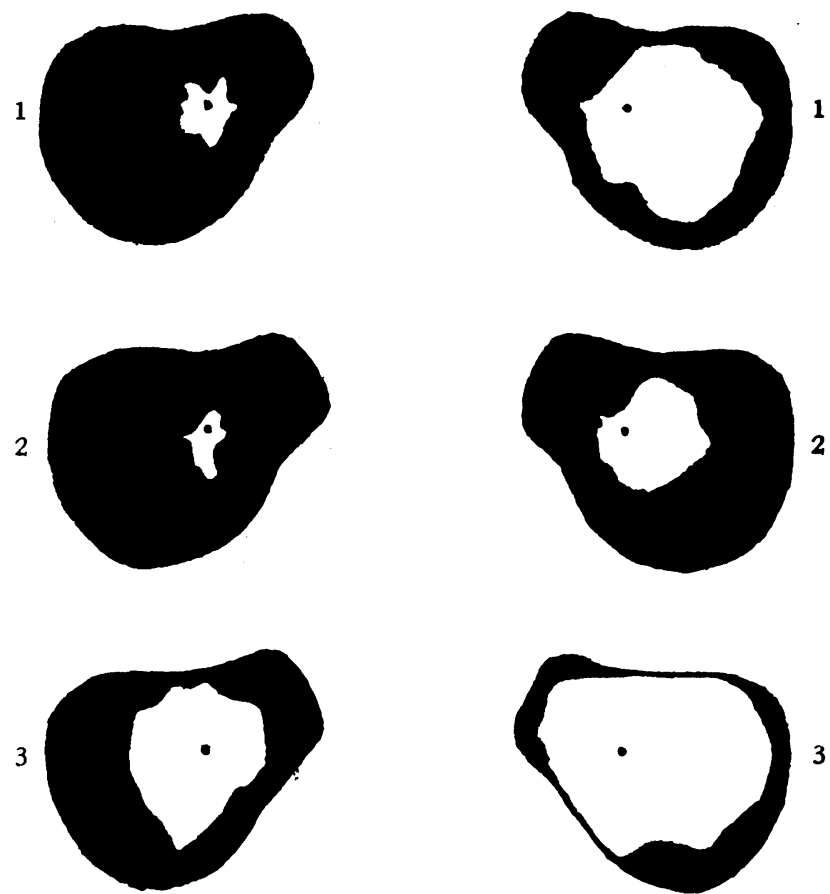

Fields from a Case of Bilateral SPHENOIDAL EMPYEMA.

Central spot represents fixation point,

White area represents patient's visual field.

Black area represents amount by which patient's field is less than the normal,

The second fields were taken on January 28 ; his visual acuity had then declined to 6/24 each eye, uncorrected.

On February 3, Mr. Lowndes Yates explored his sphenoidal sinuses, and withdrew 3 c.c. of pus from the right side and 2 c.c. from the left.

Next day, vision had improved to $6 / 12$ right, 6/18 left.

In the evening of February 6 , the patient had a very severe headache followed by a sensation of swelling the next morning, and in the afternoon a feeling as if the swelling had burst. On the following day the third pair of fields was taken. Colour vision was normal for the smallest coloured objects. On February 10 , his corrected macular visual acuity was :--

0. D. $=\bar{c} .-0.50$ D. cyl. ax. $\left.150^{\circ}=6 / 6 \quad\right\}=6 / 5$, and $0 . \mathrm{S} .=\overline{\mathrm{c}} .+0.25$ D. sph. $\leftrightharpoons-0.50$ D. cyl. ax. $\left.60^{\circ}=6 / 6\right\}$ J.1. easily

Although the field contraction is a little unusual, and the boundaries of the relative scotoma could not be definitely mapped out, there seems adequate reason for this case to be regarded as one of 
retro-bulbar neuritis directly due to a nasal sinus infection; the manner in which the conducting power of the optic nerve was inhibited, whether by toxins or otherwise, is not clear.

I acknowledge my indebtedness to Mr. Cridland for his permission to publish this case.

\section{ANNOTATION}

\section{The Social Work of a large Hospital}

There is a side of the work of a large hospital of which the surgeon sees little and the student practically nothing. It plays, nevertheless, a most important part in the successful treatment of many of their patients. The Lady Almoner, Miss. M. W. Edminson, has just issued a report on the work of the Samaritan Fund of the Royal London Ophthalmic Hospital. In this report a new departure is made to enable the reader to visualise by the aid of diagrams the nature of the disease, the assistance found necessary, and the institutions available for such assistance. As is to be expected in an ophthalmic hospital the most frequent recommendations are made to the M.A.B. Schools at White Oak, Swanley. Some of the facts relating to the group of children sent to Swanley have been collected and classified in the report for the years 1924 and 1925, when 50 children between the ages of 2 and .15 were transferred there.

"These children were suffering from phlyctenular ophthalmia, keratitis, blepharitis, interstitial keratitis (two cases) and trachoma (one case). The purpose of the investigation was to discover not only how many were, on their return, reported by the surgeon as free from all signs of active disease, but also how many had remained without relapse for at least a period of twelve months. The Hospital notes could not be taken as final evidence in concluding whether a relapse had occurred because it was possible that the ophthalmia had recurred without the child being brought again to Moorfields, or that the parent had taken him elsewhere for treatment. Each patient was therefore visited at home and the parents' co-operation was enlisted in discovering what had happened. The children, before being sent to Swanley, had suffered from eye disease for prolonged periods, only twelve out of the total having been affected for a period less than six months, and some had been attending as out-patients for several years. The average stay at White Oak was seven months." The final result was that 78 per cent. were sent home, not only cured but with their general health sufficiently established to preclude the chance of relapse. Such a result, only -one of the many activities of this work, speaks for itself. The success of this work affords ample evidence of the advisability of providing even greater facilities for the treatment of this class of case. 